\title{
CdSe Quantum Dots for Solar Cell Devices
}

\author{
A. B. Kashyout, ${ }^{1}$ Hesham M. A. Soliman, ${ }^{1}$ Marwa Fathy, ${ }^{1}$ E. A. Gomaa, ${ }^{2}$ and Ali A. Zidan ${ }^{1}$ \\ ${ }^{1}$ Advanced Technology and New Materials Research Institute, City of Scientific Research and Technological Applications, \\ New Borg El-Arab City, Alexandria 21934, Egypt \\ ${ }^{2}$ Department of Chemistry, Faculty of Science, Mansoura University, Mansoura 35516, Egypt
}

Correspondence should be addressed to A. B. Kashyout, hady8@yahoo.com

Received 6 January 2012; Accepted 6 February 2012

Academic Editor: Mohamed Sabry Abdel-Mottaleb

Copyright () 2012 A. B. Kashyout et al. This is an open access article distributed under the Creative Commons Attribution License, which permits unrestricted use, distribution, and reproduction in any medium, provided the original work is properly cited.

CdSe quantum dots have been prepared with different sizes and exploited as inorganic dye to sensitize a wide bandgap $\mathrm{TiO}_{2}$ thin films for QDs solar cells. The synthesis is based on the pyrolysis of organometallic reagents by injection into a hot coordinating solvent. This provides temporally discrete nucleation and permits controlled growth of macroscopic quantities of nanocrystallites. XRD, HRTEM, UV-visible, and PL were used to characterize the synthesized quantum dots. The results showed CdSe quantum dots with sizes ranging from $3 \mathrm{~nm}$ to $6 \mathrm{~nm}$ which enabled the control of the optical properties and consequently the solar cell performance. Solar cell of $0.08 \%$ performance under solar irradiation with a light intensity of $100 \mathrm{~mW} / \mathrm{cm}^{2}$ has been obtained. $\mathrm{CdSe} / \mathrm{TiO}_{2}$ solar cells without and with using mercaptopropionic acid (MPA) as a linker between CdSe and $\mathrm{TiO}_{2}$ particles despite a $V_{\mathrm{oc}}$ of $428 \mathrm{mV}, J_{\mathrm{sc}}$ of $0.184 \mathrm{mAcm}^{-2}$, FF of 0.57 , and $\eta$ of $0.05 \%$ but with linker despite a $V_{\mathrm{oc}}$ of $543 \mathrm{mV}, J_{\mathrm{sc}}$ of $0.318 \mathrm{mAcm}^{-2}, \mathrm{FF}$ of 0.48 , and $\eta$ of $0.08 \%$, respectively.

\section{Introduction}

Nanocrystals or quantum dots (QDs) are currently a subject of intense research activity targeting a wide range of potential applications, including light-emitting diodes (LEDs) [1, 2], photovoltaics [3, 4], single-electron transistors [5], and fluorescent tags for biological imaging $[6,7]$. The utility of nanocrystals lies in their unique size-dependent optical and electronic properties, chiefly a size-tunable optical absorption and emission spectra [8]. According to these unique properties, the recent interest in utilizing semiconductor nanocrystals (or quantum dots) for harvesting light energy has drawn great attention toward metal-chalcogenide-based system $[4,9]$. Of particular interest are $\mathrm{CdX}$ and $\mathrm{PbX}(\mathrm{X}=$ $\mathrm{S}$, Se, and Te) QDs, which have relatively small bandgaps and thus are capable of harvesting photons in the visible and infrared region [10]. These materials have been employed in three different types of quantum dot solar cells [11]: (i) metal junction solar cells, (ii) polymer hybrid solar cells, and (iii) quantum dot-sensitized solar cells (QDSCs). In the metal junction solar cells, charge separation is achieved at metal semiconductor interface upon visible laser excitation. The polymer hybrid solar cells utilize blends of conducting polymers (e.g., poly(3-hexylthiophene)) and QDs to facilitate charge separation and charge transport. In the case of the QDSCs, excited electrons of semiconductor nanocrystals are injected into a large bandgap semiconductor such as $\mathrm{TiO}_{2}$ or $\mathrm{ZnO}$, and holes are scavenged by a redox couple [4].

Research on the preparation of the QDs concentrates on the syntheses and characterizations of the monodisperse QDs, especially the studies of nucleation and growth mechanisms as well as the improvement of the luminescence quantum yields (QY). The most popular route to synthesize CdSe quantum dots is the method using organometallic compounds [12]: dimethylcadmium $\left(\left(\mathrm{CH}_{3}\right)_{2} \mathrm{Cd}\right)$ reacts with a selenium reagent in the presence of trioctylphosphine oxide (TOPO) surfactant at high temperature $\left(300^{\circ} \mathrm{C}\right)$. Careful control of reaction conditions produces CdSe quantum dots that are quite homogeneous in size and tunable in size from 2 to $8 \mathrm{~nm}$. However, $\left(\left(\mathrm{CH}_{3}\right)_{2} \mathrm{Cd}\right)$ is extremely toxic, pyrophoric, unstable at room temperature, and explosive at elevated temperatures by releasing large amounts of gas. Because of these reasons, the $\left(\mathrm{CH}_{3}\right)_{2} \mathrm{Cd}-$ related schemes require very restricted equipments and conditions and are not suitable for large-scale synthesis. In a recent development, Z. A. Peng and X. Peng [13] reported 


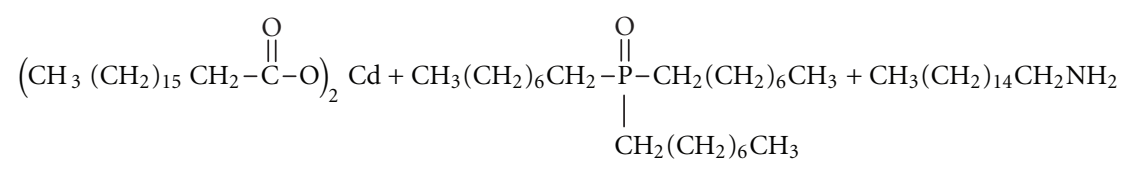

Cadmium stearate

Trioctylphosphine oxide Hexadecylamine
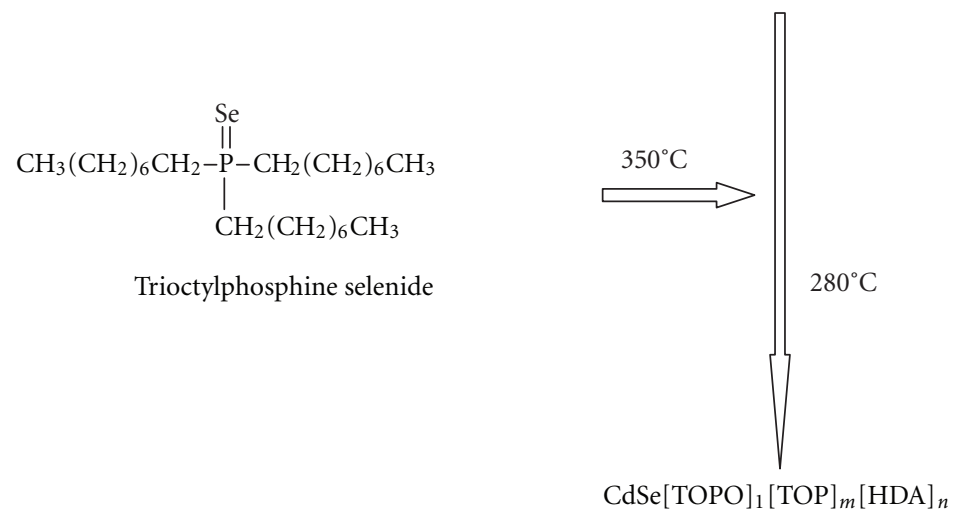

FIGURE 1: Scheme for the preparation reaction of CdSe QDs.

the use of less toxic and reactive cadmium oxide $(\mathrm{CdO})$ with hexylphosphonic acid (HPA) or tetradecylphosphonic acid (TDPA), as an alternative to $\left(\mathrm{CH}_{3}\right)_{2} \mathrm{Cd}$ in TOPO syntheses of CdX.

In this paper, we chose different reagents as reaction media and low-toxic, air-stable inorganic reagents as precursors to synthesize CdSe QDs such as CdO instead of dimethyl cadmium and study the effect of solvent (TOPO \& TOP) and the ratio of CdO to Se on the growth and the yield of QDs. Then use these CdSe QDs as sensitizer for $\mathrm{TiO}_{2}$ nanoparticles prepared by Kashyout et al. 2010 [14]. $\mathrm{TiO}_{2}$ films prepared by doctor-blade technique on ITO $(14 \Omega / \square) /$ glass that prepared by Kashyout et al. 2011 [15] using sputtering technique. QDs linked to $\mathrm{TiO}_{2}$ film by using 3-mercaptopropionic acid as a linker [16].

\section{Materials and Methods}

2.1. Materials. Cadmium oxide CdO (99.5\%, Alpha), selenium powder Se (99\%, Alfa Aesar), trioctylphosphine (TOP) (99\%, Aldrich), trioctylphosphine oxide (TOPO) (99\%, Aldrich), hexadecylamine (HDA) (99\%, Aldrich), Stearic acid (SA) (99.5\%, Aldrich), and 3-mercaptopropionic acid (MPA) (99\%, Alfa Aesar).

\subsection{Methods}

2.2.1. Preparation of $C d S e Q D s$. This reaction procedure was originally reported by Z. A. Peng and X. Peng [13]. Figure 1 shows scheme for the preparation reaction of CdSe QDs. Se injection solution was prepared under nitrogen by mixing Se powder and TOP in a scintillation vial, which was capped by a rubber septum and fixed with two turns of $\mathrm{Cu}$ wire. After $\sim 30$ min of heating $\left(\sim 150^{\circ} \mathrm{C}\right.$, on a hot plate $)$ and vigorously stirring with a PTFE stir bar, the suspended Se became soluble to afford a light-yellow solution. The Se solution is allowed to cool to room temperature in the presence of nitrogen gas instead of air before injection into a heated $\mathrm{Cd}$ solution.

In a laminar flow hood, $\mathrm{CdO}$ and $\mathrm{SA}$ were loaded into a 3-neck round-bottom flask. The reaction flask is heated to $150^{\circ} \mathrm{C}$ in air with a round bottom heating mantle. After $\sim 30 \mathrm{~min}$, the reddish-brown slurry became optically clear indicating formation of cadmium stearate. To the hot reaction vessel, HDA and TOPO were added. The reaction flask was backfilled with $\mathrm{N}_{2}$ and heated to $320^{\circ} \mathrm{C}$. At this temperature, the selenium solution was swiftly injected into the reaction flask.

Upon injection, the solution temperature dropped to $280^{\circ} \mathrm{C}$. The solution was maintained at $280^{\circ} \mathrm{C}$ for the desired amount of time to reach the desired NC size. The roundbottom flask was then removed from the heating mantle and quickly cooled to $\sim 70^{\circ} \mathrm{C}$. CdSe QDs washed more than three times by using ethanol and acetone.

Table 1 illustrates the different preparation parameters, which are used for the preparation of CdSe QDs.

2.2.2. Preparation of $\mathrm{TiO}_{2}$ Thin Films. The ITO/glass which is used as current collector $(14 \Omega / \square)$ [15] was first cleaned in water and then acetone using an ultrasonic bath for $15 \mathrm{~min}$. A layer of $\mathrm{TiO}_{2}$ paste was coated on the ITO glass plates by spinner coating method (wafer spinner machine (100 rpm, $2 \mathrm{~min})$ ), then allowed to dry in air and followed by heat treatment at $450^{\circ} \mathrm{C}$ for $30 \mathrm{~min}$. This procedure with $\mathrm{TiO}_{2}$ paste (coating, drying, and heat treatment) was repeated to get the appropriate thickness of about $10 \mu \mathrm{m}$ for the working electrode. 
TABLE 1: Different preparation parameters used for the preparation of CdSe QDs.

\begin{tabular}{lccccccc}
\hline $\begin{array}{l}\text { Sample } \\
\text { no. }\end{array}$ & $\begin{array}{c}\text { CdO } \\
(\mathrm{gm})\end{array}$ & $\begin{array}{c}\text { Se } \\
(\mathrm{gm})\end{array}$ & $\begin{array}{c}\text { TOPO } \\
(\mathrm{gm})\end{array}$ & $\begin{array}{c}\text { TOP } \\
(\mathrm{mL})\end{array}$ & $\begin{array}{c}\text { HAD } \\
(\mathrm{gm})\end{array}$ & $\begin{array}{c}\text { SA } \\
(\mathrm{gm})\end{array}$ & $\begin{array}{c}\text { Reaction } \\
\text { time }(\mathrm{sec} .)\end{array}$ \\
\hline S1 & 0.0829 & 0.051 & 9.83 & 6.25 & 9.73 & 0.8974 & 60 \\
S2 & 0.0829 & 0.051 & 9.83 & 6.25 & 9.73 & 0.8974 & 40 \\
S3 & 0.0829 & 0.051 & 9.83 & 6.25 & 9.73 & 0.8974 & 20 \\
S4 & 0.0829 & 0.051 & 9.83 & 6.25 & 9.73 & 0.8974 & 10 \\
S5 & 0.0829 & 0.051 & 10 & 10 & 9.73 & 0.8974 & 60 \\
S6 & 0.0829 & 0.051 & 15 & 10 & 9.73 & 0.8974 & 60 \\
S7 & 0.0829 & 0.051 & 5 & 10 & 9.73 & 0.8974 & 60 \\
S8 & 0.0829 & 0.102 & 10 & 10 & 9.73 & 0.8974 & 60 \\
S9 & 0.0829 & 0.153 & 10 & 10 & 9.73 & 0.8974 & 60 \\
S10 & 0.0829 & 0.255 & 10 & 10 & 9.73 & 0.8974 & 60 \\
S11 & 0.0829 & 0.357 & 10 & 10 & 9.73 & 0.8974 & 60 \\
\hline
\end{tabular}

2.2.3. Preparation of $\mathrm{CdSe} \mathrm{QDs} / \mathrm{TiO}_{2}$ Films. $\mathrm{TiO}_{2}$ thin films were dipped into a solution of $\mathrm{N}_{2}$ purged acetonitrile containing carboxyalkanethiol such as 3-mercaptopropionic acid ( $1: 10$ ratio) for $24 \mathrm{hrs}$. Resulting $\mathrm{TiO}_{2}$ films, functionalized with these bifunctional surface modifiers, were washed with both acetonitrile and toluene and then immersed in a suspension of CdSe solution for $24 \mathrm{hrs}$ [17].

2.2.4. Fabrication of $\mathrm{QDs} / \mathrm{TiO}_{2}$ Solar Cells. The counter electrode was placed directly on the top of the $\mathrm{QDs} / \mathrm{TiO}_{2}$ film, supported by the conducting glass sheet. Both electrodes were clamped tightly together. Drops of electrolyte (0.5 M LiI/50 $\mathrm{mM} \mathrm{I}_{2}$ in solvent of 3-methoxypropionitrile) and $0.5 \mathrm{M} 4$-tert-butylpyridine were added to the standard electrolyte solution in order to increase the stability of the electrolyte. The $\mathrm{QDs} / \mathrm{TiO}_{2}$ film was illuminated through the conducting glass substrate to measure the cell performance.

2.2.5. Characterization of CdSe QDs. The structural properties of these organic species were confirmed by the powder X-ray diffraction (XRD) using (Shimadzu 7000, Japan) diffractometer, operating with $\mathrm{Cu} \mathrm{K} \alpha$ radiation $(\lambda$ $=0.15406 \mathrm{~nm}$ ) generated at $30 \mathrm{kV}$ and $30 \mathrm{~mA}$. Scans were done at $4^{\circ} \mathrm{min}^{-1}$ for $2 \theta$ values between 20 and $60^{\circ}$. The morphologies and the crystallite size of $\mathrm{TiO}_{2}$ nanoparticles were observed by high-resolution transmission electron microscopy (HRTEM) (JEOLJEM-2100F, Japan). To identify and characterize the organic species on the surfaces, the Fourier transform infrared spectroscopy (FT-IR) spectra were obtained using a Shimadzu FTIR-8400 S, Japan. The absorption spectra and their photoluminescence properties were characterized by means of LABOMED double-beam UV-Vis spectrophotometer with spectrum range from 190 to $1100 \mathrm{~nm}$ and using a Varian Cary Eclipse spectrofluorometer.

2.2.6. Characterization of $\mathrm{QDs} / \mathrm{TiO}_{2}$ Solar Cells. The QDs/ $\mathrm{TiO}_{2}$ solar cell performance was measured using solar simulator device (PET Photo Emission Tech., Inc., USA). The solar simulator simulates the AM1.5 spectrum by using xenon lamp, and the light intensity could be controlled from

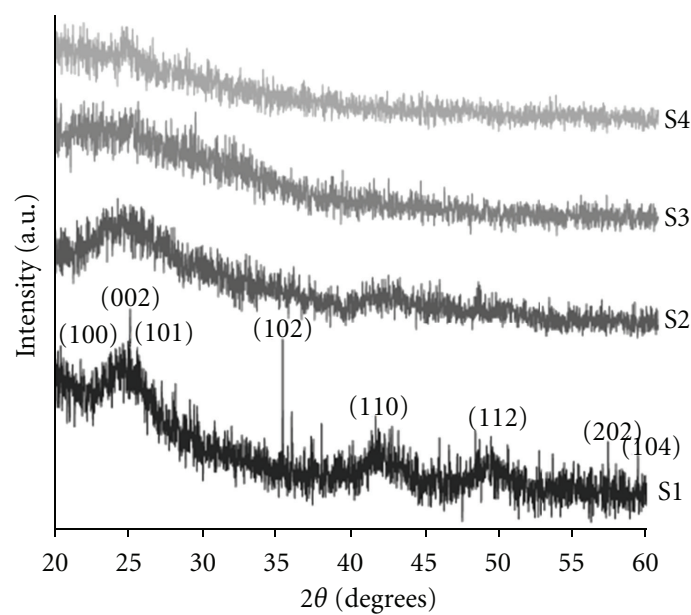

FIGURE 2: XRD spectra of CdSe samples using different growth rate.

TABLE 2: Effect of TOPO/TOP ratio on the CdSe QDs yield.

\begin{tabular}{lcccc}
\hline Sample & TOP $(\mathrm{mL})$ & TOPO $(\mathrm{gm})$ & Yield $(\mathrm{gm})$ & Yield $(\%)$ \\
\hline S5 & 10 & 10 & 0.14 & 29 \\
S6 & 15 & 10 & 0.13 & 27 \\
S7 & 5 & 10 & 0.12 & 25 \\
\hline
\end{tabular}

0.1 Sun to 1.25 Sun. The cell ambient temperature was controlled at $25^{\circ} \mathrm{C}$ using a control system attached to the solar simulator.

\section{Results and Discussion}

3.1. Structural Analysis. Figure 2 (S1, S2, S3, and S4) shows the XRD of CdSe quantum dots with different growth rates as shown in Table 1. The XRD spectra of S1 and S2 exhibit clear peaks that confirm the wurtzite structure with (100), (002), (101), (102), (110), (112), (202), and (104) planes according to the JCPD no. 08-0456, but, for S3 and S4, it gives amorphous structure, which mean that, when the particle size became small, the sample loses its crystalline structure and transfers into amorphous structure.

The crystallite size of different samples can be determined from the broadening of corresponding X-ray spectral peaks by the Scherrer formula:

$$
L=\frac{K \lambda}{(\beta \cos \theta)}
$$

where $L$ is the crystallite size, $\lambda$ is the wavelength of the $\mathrm{X}$ ray radiation ( $\left.\mathrm{Cu} K_{\mathrm{a}} \alpha=0.15418 \mathrm{~nm}\right), K$ is usually taken as 0.89 , and $\beta$ is the line width at half-maximum height, after subtraction of equipment broadening. It was found that the crystallite size value of S1 and S2, is 4.5 and 4, respectively.

Table 2 illustrates the effect of using different TOPO/TOP $(\mathrm{wt} / \mathrm{vol})$ ratio on the growth rate of the CdSe QDs. It was found that the growth rate of particles was decreased as the ratio of TOPO/TOP increases. Figure 3 shows the absorbance curve of different CdSe samples (S5, S6, and S7) prepared using different TOPO/TOP ratio. It was found 


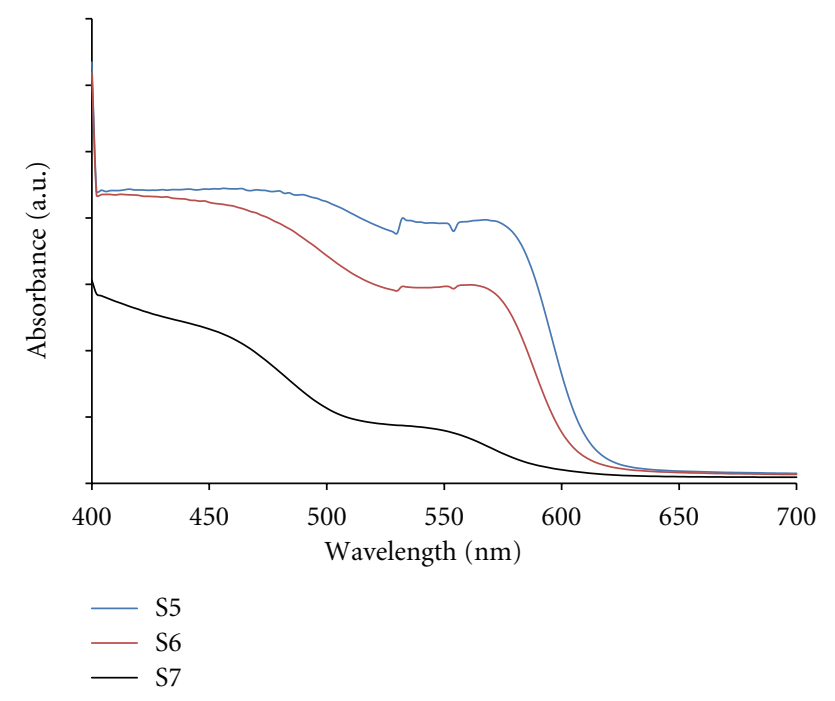

FIgURe 3: Absorbance spectra of CdS QDs prepared using different TOPO/TOP ratio.

TABle 3: Effect of CdO/Se molar ratio on the CdSe stoichiometry and QDs yield.

\begin{tabular}{lcccc}
\hline Samples & $\begin{array}{c}\text { CdO:Se } \\
\text { ratio }\end{array}$ & $\begin{array}{c}\text { Cd:Se atomic } \\
\text { ratio }\end{array}$ & Yield (gm) & Yield (\%) \\
\hline S8 & $1: 1$ & 1.27 & 0.12 & 25 \\
S9 & $1: 3$ & 1.42 & 0.13 & 27 \\
S10 & $1: 5$ & 1.32 & 0.13 & 27 \\
S11 & $1: 7$ & - & No reaction & No reaction \\
\hline
\end{tabular}

that the absorbance peak for samples S5, S6, and S7 was shifted to lower value of wavelength with decrease of the particle growth rate.

Table 3 illustrates the effect of using different $\mathrm{CdO} / \mathrm{Se}$ molar ratios on the stoichiometry of CdSe QDs using the TOPO/TOP ratio value of $1: 1$. It is found that the atomic ratio of $\mathrm{Cd} / \mathrm{Se}$ is $1.27,1.42$, and 1.32 for $\mathrm{CdO} / \mathrm{Se}$ ratios of $1: 1,1: 3$, and $1: 5$, respectively. When increasing the $\mathrm{CdO} / \mathrm{Se}$ ratio to $1: 7$, no reaction was occurred. This result indicates that controlling the $\mathrm{Cd} / \mathrm{Se}$ ratio in the precursors affects the quantum dot chemicals properties with a small effect on their yield.

Energy dispersive X-ray analysis (EDX) indicates that the quantum dots are nonstoichiometric, showing a molar ratio of $\mathrm{Cd} / \mathrm{Se}$ about 1.27 (sample S8) in Table 2. This result is similar to the data previously reported by other authors such as Moreels et al. [18] and Taylor et al. [19] who found similar ratios between the metal $\mathrm{M}(\mathrm{Cd})$ and the counterion $\mathrm{X}(\mathrm{Se})$ in analogous systems for the PbSe QDs. Owen et al. [20] proposed a sphere-like structure for these materials, in which $\mathrm{Cd}^{2+}$ ions are present on the QDs surface, which justifies the nonstoichiometry so that metal ions can easily interact with the molecules of a ligand shell by coordination [21].

3.2. Morphological Analysis. HRTEM reveals information about the particle size and shape. Figure 4 shows the HRTEM images of the S1 example for of CdSe quantum dots before

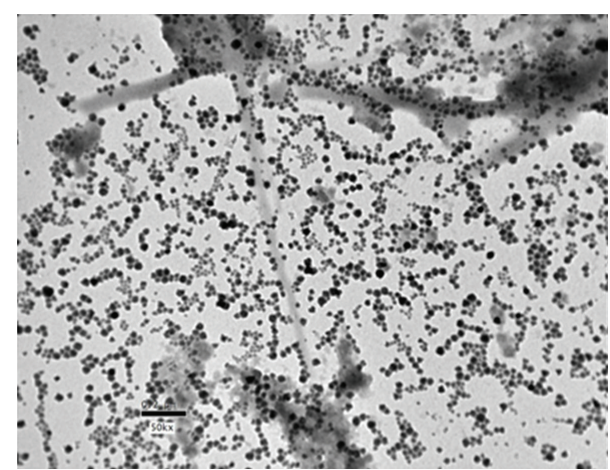

FIGURE 4: HRTEM images of CdSe QDs without purification.

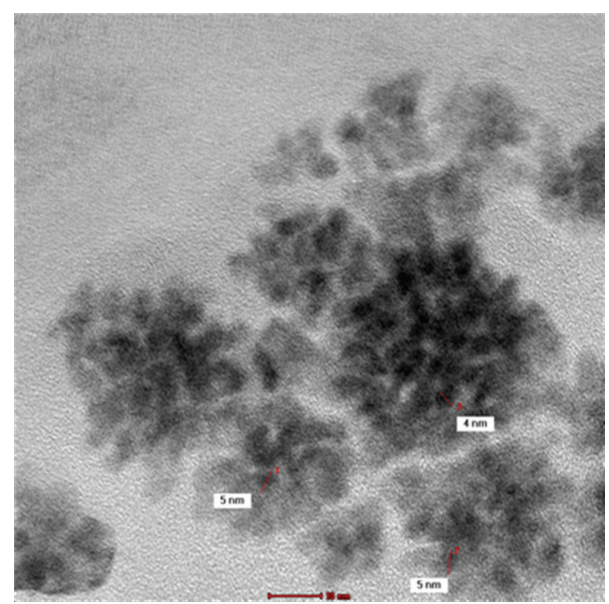

(a)

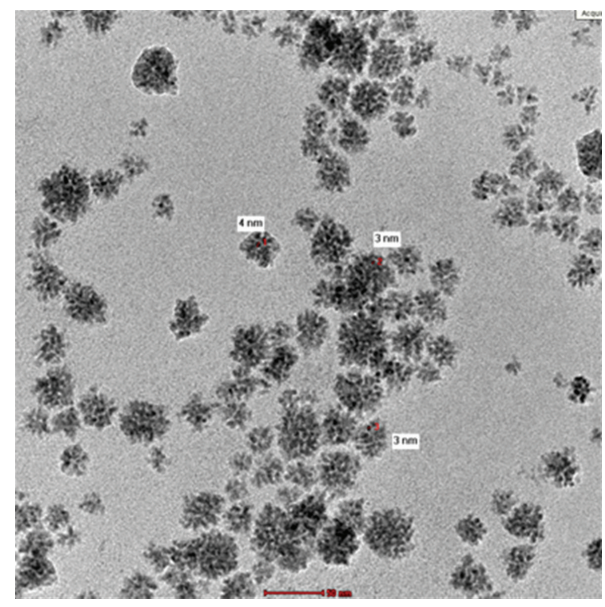

(b)

FIgURE 5: HRTEM images of CdSe QDs after purification.

purification from the excess of ligands. CdSe quantum dots are collected on the surface of large chain ligands.

The concentration of the nanocrystals in samples were determined by the number of cadmium atoms contained in the samples and the size of the nearly monodisperse particles. Therefore, it was critical to remove any unreacted cadmium precursors in the sample. The extraction method 


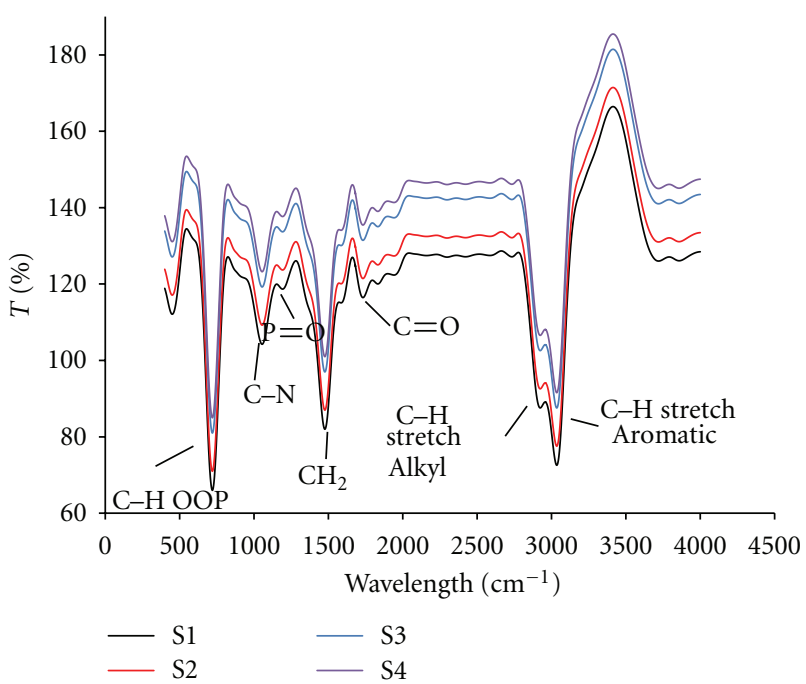

FIGURE 6: FT-IR spectra of CdSe QDs soluble in toluene.

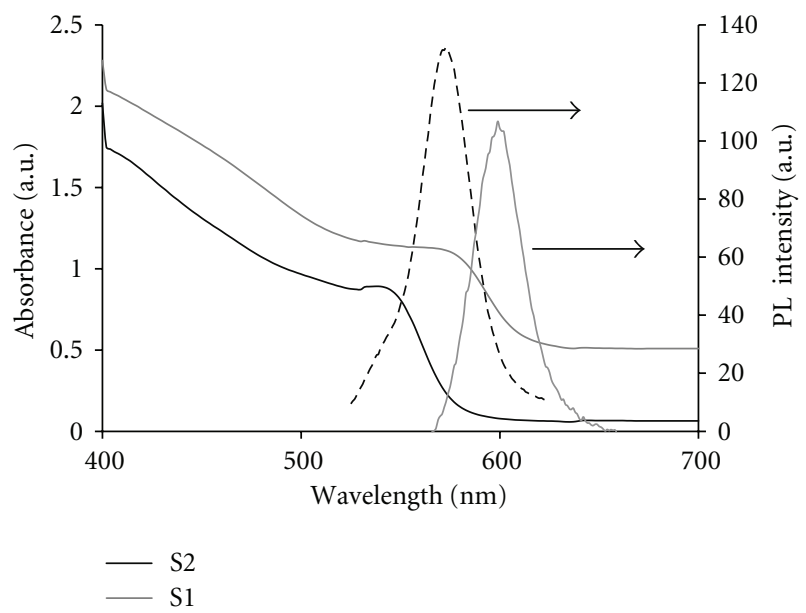

(a)

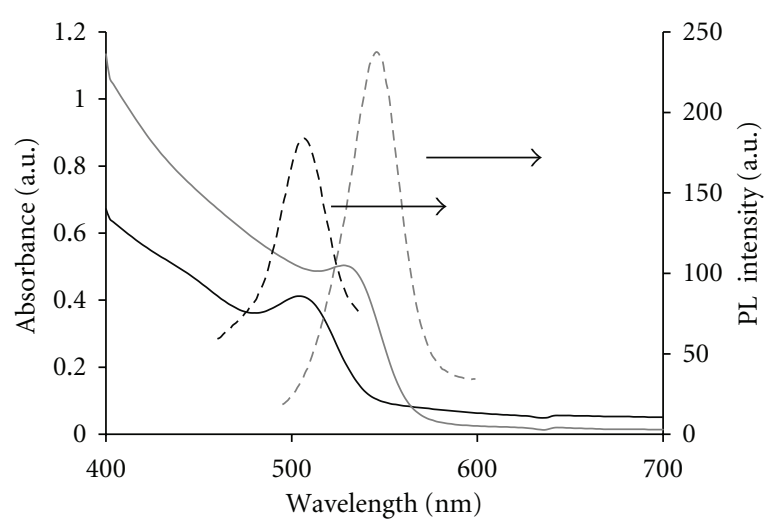

- S4

$-\mathrm{S} 3$

(b)

FIGURE 7: UV-Vis and photoluminescence spectra of the representative nanocrystalline samples.

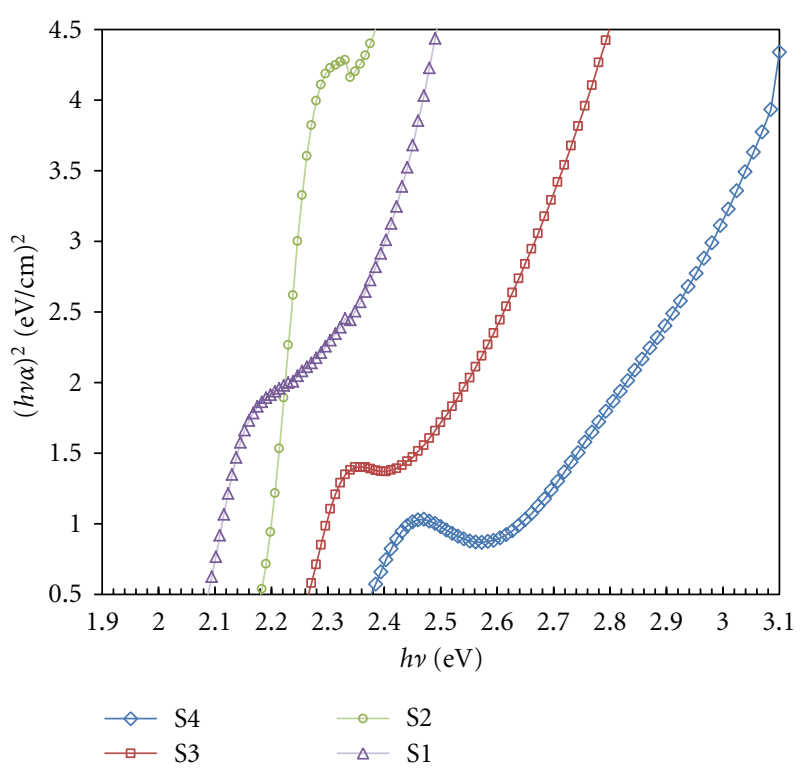

Figure 8: Bandgap of CdSe samples.

is based on the fact that the solubilities of the un-reacted cadmium precursors used in the synthesis and the resulting nanocrystals were significantly different in a two-phase system, ethanol and octadecane.

Figure 5 shows the HRTEM images of CdSe powder after purification. The particle size was determined to have value of $2-4 \mathrm{~nm}$. These are consistent with the result of X-ray diffraction spectrum. Also, the nanocrystals were dispersed well, and no aggregation was detected.

Figure 6 shows the FT-IR spectra of S1, S2, S3, and S4. CdSe QDs are soluble in toluene after purification. On the basis of the FT-IR data, the surface of the CdSe QDs is mainly coated with alkyl ligands. Flexible organic molecule such as phosphine alkyl ligands provides repulsive interactions between the QDs in toluene, thus preventing aggregation. Others show $3417 \mathrm{~cm}^{-1}$ at $\mathrm{OH}, 2360 \mathrm{~cm}^{-1}$ at $\mathrm{PH} 3$, $1464 \mathrm{~cm}^{-1}$ at $\mathrm{CH}_{2}, 1155 \mathrm{~cm}^{-1}$ at $\mathrm{P}=\mathrm{O}$ functional group [22].

3.3. Optical Analysis of CdSe QDs. Figure 7 shows the absorption and photoluminescence (PL) spectra $(410 \mathrm{~nm}$ excitation) for different size of CdSe QDs (S1, S2, S3, and S4). For the absorption spectra, all CdSe samples clearly show the effect of quantum confinement. These particles exhibit absorption in the visible region with an onset corresponding to the particle size. The shift of the onset absorption peaks to higher wavelengths $(506,530,543$, and $577 \mathrm{~nm}$ ) with increasing the particle size represents size quantization effects in these particles.

According to the literature, Yu et al., 2003, developed a theoretical method to calculate the QDs size using the position of first excitonic peak. The particle size of the different samples was determined using

$$
\begin{aligned}
D= & \left(1.6122 * 10^{-9}\right) \lambda^{4}-\left(2.6575 * 10^{-6}\right) \lambda^{3} \\
& +\left(1.6242 * 10^{-3}\right) \lambda^{2}-(0.4277) \lambda+(41.57),
\end{aligned}
$$




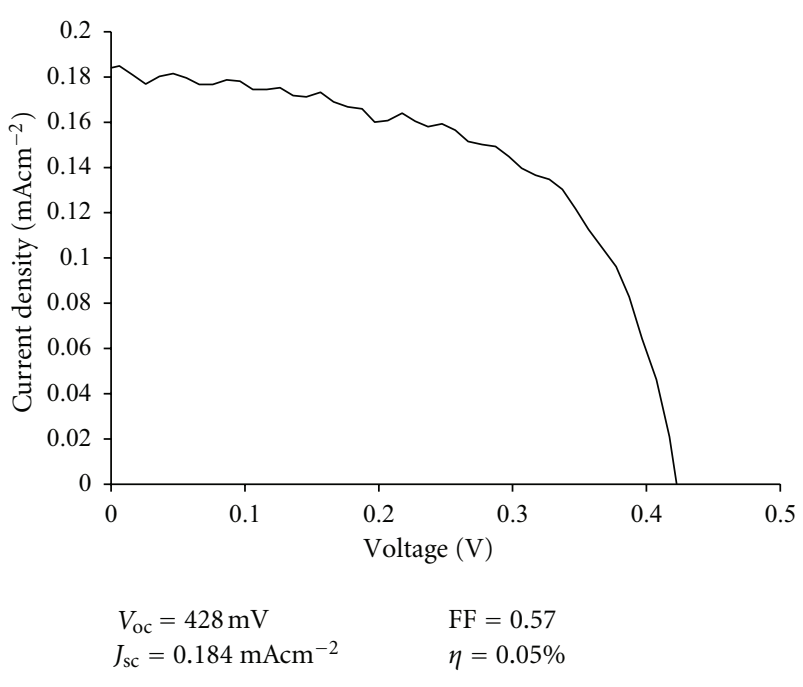

(a)

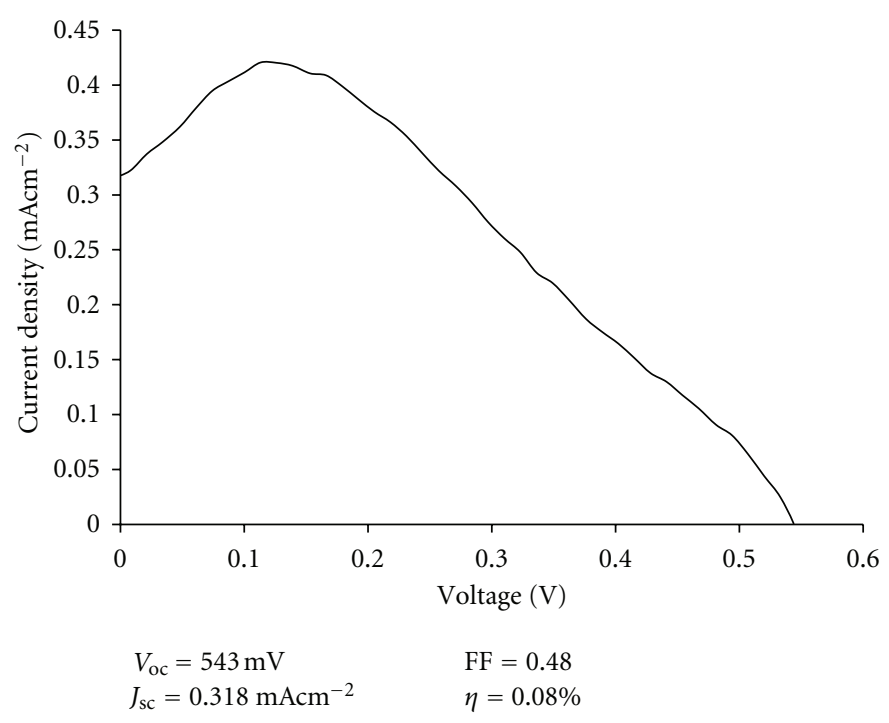

(b)

Figure 9: $I$ - $V$ curves of $\mathrm{CdSe} / \mathrm{TiO}_{2}$ solar cell, (a) without and (b) with using MPA as a linker between CdSe and TiO $\mathrm{T}_{2}$ particles.

where $D(\mathrm{~nm})$ is the size of a given sample and $\lambda(\mathrm{nm})$ is the wavelength of the first excitonic absorption peak of the corresponding sample. The calculated particle size crossponding to the wavelength of the excitonic peaks was 2.3, 2.9, 3, and $3.7 \mathrm{~nm}$ for samples S1, S2, S3, and S4, respectively.

For photoluminescence spectra, CdSe samples with particle size of $2.3,2.9,3$, and $3.7 \mathrm{~nm}$ were given emission peaks at 505, 547, 577, and $600 \mathrm{~nm}$; respectively, it means that the peaks move toward the red end of visible region with the growth temperature which expected according to the literature.

Figure 8 shows the calculated $E_{g}$ of S1, S2, S3, and S4 of CdSe QDs with different particle size. The band gap was decreased by $2.38,2.28,2.18$, and $2.08 \mathrm{eV}$ with the particle size increase of $2.3,2.9,3$, and $3.7 \mathrm{~nm}$, respectively.

The calculated diameter was used to determine the molar absorption (extinction) coefficient $(\varepsilon)$ using

$$
\varepsilon=5857(D)^{2.65}
$$

If the extinction coefficient of those nanocrystals was calculated, it would be easy to obtain the concentrations of the nanocrystals by simply taking an absorption spectrum of the sample and using Lambert-Beer's law

$$
A=\varepsilon C L
$$

where $A$ is the absorbance at the peak position of the first exciton absorption peak for a given sample. $C$ is the molar concentration $(\mathrm{mol} / \mathrm{L})$ of the nanocrystals of the sample. $L$ is the path length $(\mathrm{cm})$ of the radiation beam used for recording the absorption spectrum.

Unlike conventional organic and inorganic compounds, the concentration of colloidal nanocrystals is difficult to determine by gravimetric methods. Because the number of
TABle 4: Absorbance, particle size, extinction, and the molar concentration of CdSe DQs.

\begin{tabular}{lccccc}
\hline $\begin{array}{l}\text { Sample First excitonic } \\
\text { no. }\end{array}$ & peak $(\mathrm{nm})$ & Abs. & $\begin{array}{c}\text { Size } \\
(\mathrm{nm})\end{array}$ & $\begin{array}{c}\text { Extinction coeff. } \\
\left(\mathrm{mol}^{-1} \mathrm{~cm}^{-1} \mathrm{~L}\right)\end{array}$ & $\begin{array}{c}\text { Conc. } \\
(\mathrm{mol} / \mathrm{L}) \\
\left(10^{-6}\right)\end{array}$ \\
\hline S1 & 577 & 0.6 & 3.7 & 81150.43992 & 3.14 \\
S2 & 543 & 0.9 & 2.9 & 190860.4584 & 6.16 \\
S3 & 530 & 0.5 & 2.69 & 99040.01971 & 9.08 \\
S4 & 505 & 0.4 & 2.39 & 59194.80559 & 6.75 \\
\hline
\end{tabular}

ligands on the surface of nanocrystals is quite difficult to identify and may also vary significantly under different conditions, measurements solely based on gravimetric methods using ligands-coated nanocrystals are accurate only when the interactions between nanocrystals and ligands are sufficiently strong to withstand necessary purification procedures [23]. Therefore, the absorption spectrum method in many cases is the most practical and convenient way to determine the particle concentrations, if it is not the only possible way as shown in Table 4.

3.4. I-V Curve of $\mathrm{CdSe} / \mathrm{TiO}_{2}$ Solar Cell. For the fabricated solar cell using S1 CdSe QD, the efficiency $(\eta)$ is calculated as $\eta=J_{\mathrm{sc}} V_{\mathrm{oc}} \mathrm{FF} / I_{0}$, where $I_{0}$ is the incident irradiation power, $J_{\mathrm{sc}}$ is the short-circuit current density (current density corresponding to $V=0$ ), $V_{\mathrm{oc}}$ is the open circuit voltage (voltage corresponding to $J_{\mathrm{sc}}=0$ ), and FF is the fill factor.

Figures 9(a) and 9(b) show the $I-V$ curve of two CdSe $\mathrm{QDs} / \mathrm{TiO}_{2}$ solar cells without and with using of MPA as a linker between two semiconductors $\left(\mathrm{TiO}_{2}\right.$ and $\left.\mathrm{CdSe}\right)$ is used to enhance the adsorption of CdSe QDs on the surface of $\mathrm{TiO}_{2}$ particles and facilitate the charge transfer process from CdSe QDs to $\mathrm{TiO}_{2}$ which enhances the solar cell efficiency [17]. Simulated AM1.5G solar irradiation with 
a light intensity of $100 \mathrm{~mW} / \mathrm{cm}^{2}$ was obtained. It was found, QD solar cell without using linker despite a $V_{\mathrm{oc}}$ of $428 \mathrm{mV}, J_{\mathrm{sc}}$ of $0.184 \mathrm{mAcm}^{-2}$, FF of 0.57 , and $\eta$ of $0.05 \%$ but with linker despite a $V_{\text {oc }}$ of $543 \mathrm{mV}, J_{\mathrm{sc}}$ of $0.318 \mathrm{mAcm}^{-2}$, FF of 0.48 , and $\eta$ of $0.08 \%$.

\section{Conclusions}

Our results indicate that CdSe nanocrystals prepared by the common pyrolysis method have an average $\mathrm{Cd} / \mathrm{Se}$ stoichiometry about 1.27 and the stoichiometry is independent on the initial $\mathrm{Cd} / \mathrm{Se}$ ratio in the starting material. The results also showed CdSe quantum dots with sizes ranging from $3 \mathrm{~nm}$ to $6 \mathrm{~nm}$ which enabled the control of the optical properties and consequently the solar cell performance. Open-circuit voltage of $0.54 \mathrm{~V}$, short-circuit current density of about $0.5 \mathrm{~mA} / \mathrm{cm}^{2}$, and high fill factor of 0.57 are obtained, which are good results that should be improved through.

\section{Acknowledgment}

This work has been done under the project funded by the Science and Technology Development Fund (STDF), Ministry of Scientific Research, Project ID: 1414, "Quantum Dots Nanomaterials Dye Sensitized Solar Cells”.

\section{References}

[1] M. J. Bowers, J. R. McBride, and S. J. Rosenthal, "White-light emission from magic-sized cadmium selenide nanocrystals," Journal of the American Chemical Society, vol. 127, no. 44, pp. 15378-15379, 2005.

[2] G. Mingyuan, C. Lesser, S. Kirstein, E. Möhwald, A. L. Rogach, and H. Weller, "Electroluminescence of different colors from polycation/CdTe nanocrystal self-assembled films," Journal of Applied Physics, vol. 87, no. 5, pp. 2297-2302, 2000.

[3] H. J. Lee, J. H. Yum, H. C. Leventis et al., "CdSe quantum dot-sensitized solar cells exceeding efficiency $1 \%$ at full-sun intensity," Journal of Physical Chemistry C, vol. 112, no. 30, pp. 11600-11608, 2008.

[4] J. H. Bang and P. V. Kamat, "Quantum dot sensitized solar cells. A tale of two semiconductor nanocrystals: CdSe and CdTe," ACS Nano, vol. 3, no. 6, pp. 1467-1476, 2009.

[5] D. L. Klein, R. Rotht, A. K. L. Lim, A. P. Alivisatosti, and P. L. McEuen, "A single-electron transistor made from a cadmium selenide nanocrystal," Nature, vol. 389, no. 6652, pp. 699-701, 1997.

[6] I. L. Medintz, H. T. Uyeda, E. R. Goldman, and H. Mattoussi, "Quantum dot bioconjugates for imaging, labelling and sensing," Nature Materials, vol. 4, no. 6, pp. 435-446, 2005.

[7] S. J. Rosenthal, I. Tomlinson, E. M. Adkins et al., "Targeting cell surface receptors with ligand-conjugated nanocrystals," Journal of the American Chemical Society, vol. 124, no. 17, pp. 4586-4594, 2002.

[8] M. A. El-Sayed, "Small is different: shape-, size-, and composition-dependent properties of some colloidal semiconductor nanocrystals," Accounts of Chemical Research, vol. 37, no. 5, pp. 326-333, 2004.

[9] A. Kongkanand, K. Tvrdy, K. Takechi, M. Kuno, and P. V. Kamat, "Quantum dot solar cells. Tuning photoresponse through size and shape control of $\mathrm{CdSe}-\mathrm{TiO}_{2}$ architecture," Journal of the American Chemical Society, vol. 130, no. 12, pp. 4007-4015, 2008.

[10] D. R. Baker and P. V. Kamat, "Photosensitization of $\mathrm{TiO}_{2}$ nanostructures with CdS quantum dots: particulate versus tubular support architectures," Advanced Functional Materials, vol. 19, no. 5, pp. 805-811, 2009.

[11] A. J. Nozik, "Quantum dot solar cells," Physica E, vol. 14, no. 1-2, pp. 115-120, 2002.

[12] C. B. Murray, D. J. Norris, and M. G. Bawendi, "Synthesis and characterization of nearly monodisperse $\mathrm{CdE}(\mathrm{E}=$ sulfur, selenium, tellurium) semiconductor nanocrystallites," Journal of the American Chemical Society, vol. 115, no. 19, pp. 87068715, 1993.

[13] Z. A. Peng and X. Peng, "Formation of high-quality CdTe, CdSe, and CdS nanocrystals using $\mathrm{CdO}$ as precursor," Journal of the American Chemical Society, vol. 123, no. 1, pp. 183-184, 2001.

[14] A. B. Kashyout, M. Soliman, and M. Fathy, "Effect of preparation parameters on the properties of $\mathrm{TiO}_{2}$ nanoparticles for dye sensitized solar cells," Renewable Energy, vol. 35, no. 12, pp. 2914-2920, 2010.

[15] A. E.-H.B. Kashyout, M. Fathy, and M. B. Soliman, "Studying the properties of RF-sputtered nanocrystalline tin-doped indium oxide," International Journal of Photoenergy, vol. 2011, Article ID 139374, 6 pages, 2011.

[16] I. Mora-Seró, S. Giménez, T. Moehl et al., "Factors determining the photovoltaic performance of a CdSe quantum dot sensitized solar cell: the role of the linker molecule and of the counter electrode," Nanotechnology, vol. 19, no. 42, Article ID 424007, 2008.

[17] I. Robel, V. Subramanian, M. Kuno, and P. V. Kamat, "Quantum dot solar cells. Harvesting light energy with CdSe nanocrystals molecularly linked to mesoscopic $\mathrm{TiO}_{2}$ films," Journal of the American Chemical Society, vol. 128, no. 7, pp. 2385-2393, 2006.

[18] I. Moreels, B. Fritzinger, J. C. Martins, and Z. Hens, "Surface chemistry of colloidal PbSe nanocrystals," Journal of the American Chemical Society, vol. 130, no. 45, pp. 15081-15086, 2008.

[19] J. Taylor, T. Kippeny, and S. J. Rosenthal, "Surface stoichiometry of CdSe nanocrystals determined by Rutherford backscattering spectroscopy," Journal of Cluster Science, vol. 12, no. 4, pp. 571-582, 2001.

[20] J. S. Owen, J. Park, P. E. Trudeau, and A. P. Alivisatos, "Reaction chemistry and ligand exchange at cadmium-selenide nanocrystal surfaces," Journal of the American Chemical Society, vol. 130, no. 37, pp. 12279-12281, 2008.

[21] I. Concina, M. Natile, A. Braga et al., "One pot synthesis of bi-linker stabilised CdSe quantum dots," Journal of Physics: Conference Series, vol. 244, no. 1, Article ID 012067, 2010.

[22] S. H. Choi, H. Song, I. K. Park et al., "Synthesis of sizecontrolled CdSe quantum dots and characterization of CdSeconjugated polymer blends for hybrid solar cells," Journal of Photochemistry and Photobiology A, vol. 179, no. 1-2, pp. 135141, 2006.

[23] W. W. Yu, L. Qu, W. Guo, and X. Peng, "Experimental determination of the extinction coefficient of CdTe, CdSe, and CdS nanocrystals," Chemistry of Materials, vol. 15, no. 14, pp. 28542860, 2003. 


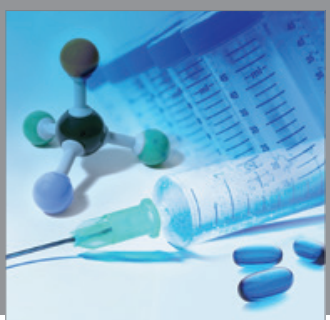

International Journal of

Medicinal Chemistry

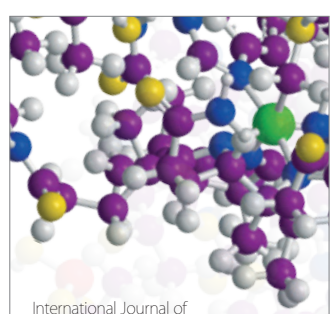

Carbohydrate Chemistry

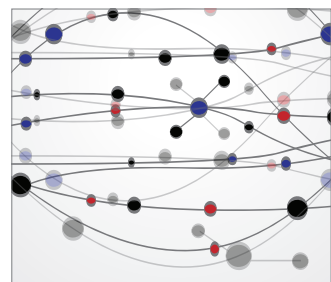

The Scientific World Journal
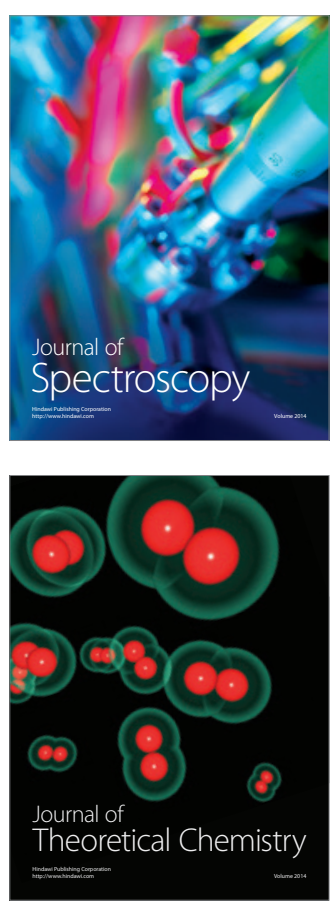
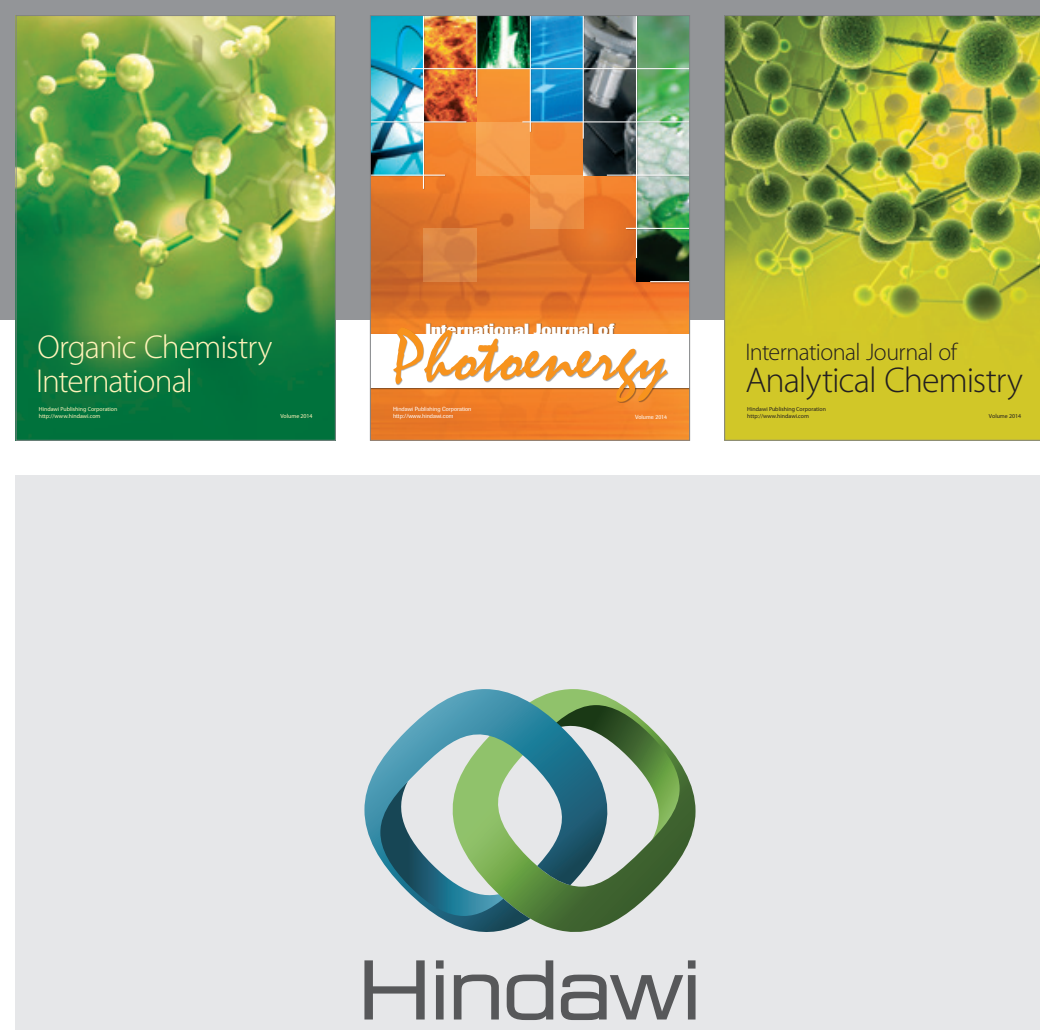

Submit your manuscripts at

http://www.hindawi.com
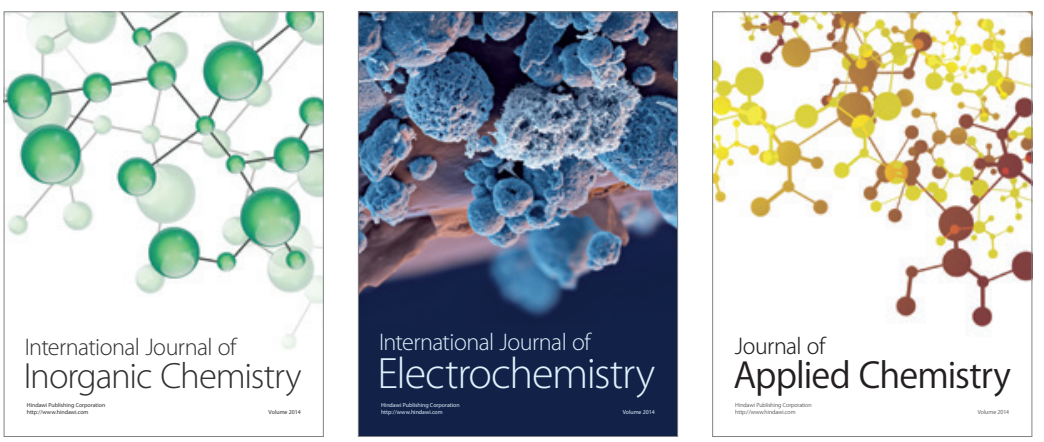

Journal of

Applied Chemistry
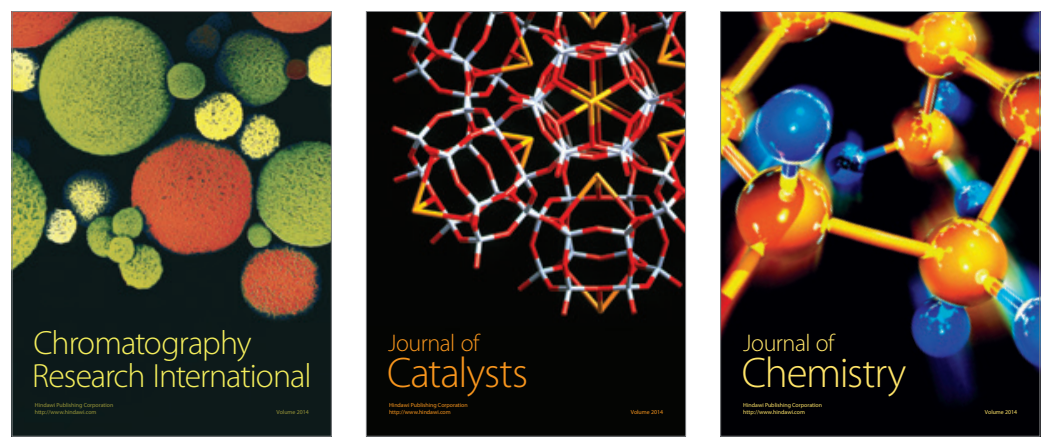
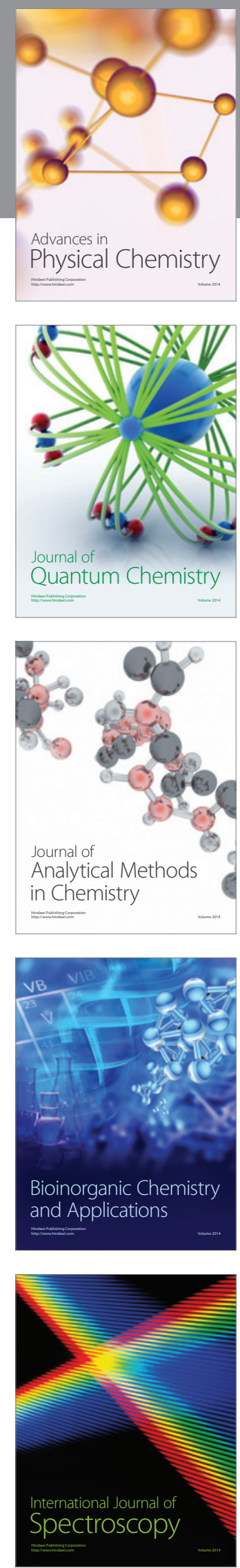